\title{
Correction to: Characterization, molecular modeling and phylogenetic analysis of a long mammalian neurotoxin from the venom of the Iranian scorpion Androctonus crassicauda
}

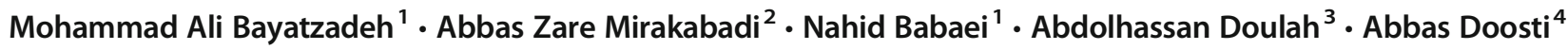 \\ Published online: 26 October 2020 \\ (C) Institute of Molecular Biology, Slovak Academy of Sciences 2020
}

Correction to: Biologia (2020) 75: 1029-1041

https://doi.org/10.2478/s11756-019-00400-1

This correction stands to correct the original article. The authorship and affiliations for the work should be noted as they appear in this correction.

Publisher's note Springer Nature remains neutral with regard to jurisdictional claims in published maps and institutional affiliations.

The online version of the original article can be found at https://oi.org/ 10.2478/s11756-019-00400-1

\footnotetext{
Mohammad Ali Bayatzadeh

m.bayatzadeh@rvsri.ac.ir

$\triangle$ Abbas Zare Mirakabadi

a.zare@rvsri.ac.ir
}

1 Department of Molecular Cell Biology and Genetics, Bushehr

Branch, Islamic Azad University, Bushehr, Iran

2 Venomous Animals and Antivenom Production Department, Agricultural Research- Education and Extension Organization, Razi Vaccine and Serum Research Institute, Hesarak,

Karaj, Alborz 3197619751, Iran

3 Department of Nursing, Ahvaz Branch, Islamic Azad University, Ahvaz, Iran

4 Biotechnology Research Center, Islamic Azad University, Shahrekord, Iran 